\title{
Hybridization and cryptic speciation in the Tropical Eastern Pacific octocoral genus Pacifigorgia
}

\author{
Angelo Poliseno ${ }^{1}$, Odalisca Breedy ${ }^{2,3,4}$, Hector M. Guzman ${ }^{4}$ and Sergio Vargas ${ }^{1, *}$
}

Author affiliations:

1. Department of Earth and Environmental Sciences, Geobiology \& Paleontology, LudwigMaximilians-Universität München. Richard-Wagner-Str. 10, 80333 Munich, Germany.

2. Centro de Investigación en Estructuras Microscópicas, Escuela de Biología, Universidad de Costa Rica. P.O. Box 11501-2060.

3. Centro de Investigación en Ciencias del Mar y Limnología, Escuela de Biología, Universidad de Costa Rica. P.O. Box 11501-2060.

4. Smithsonian Tropical Research Institute, P.O. Box 0843-03092, Panama, Republic of Panama

*Corresponding author: sergio.vargas@Imu.de

\section{Abstract}

The shallow waters of the Tropical Eastern Pacific (TEP) harbor a species-rich octocoral fauna, with seven genera and 124 octocoral species described to date for the region. Of these lineages, Pacifigorgia, with 35 species, is by far the most speciose and abundant shallow-water octocoral occurring in the region. The speciation mechanisms resulting in this remarkable diversity remain speculative, despite the extensive taxonomic and molecular systematic research conducted so far in the TEP. Using genome-wide SNP markers, we provide evidence for hybridization and extensive cryptic speciation in Pacifigorgia, suggesting that the genus' diversity has been underestimated by traditional and molecular systematic research. Our study highlights the difficulties faced by both traditional taxonomy and single-marker based molecular approaches to characterize octocoral diversity and evolution, and the role genome-wide molecular studies coupled to morphological research play to advance our understanding of this group.

\section{Introduction}

Among Tropical Eastern Pacific (TEP) octocorals, Pacifigorgia (Fig. 1) represents the most species-rich genus with about 35 valid species described to date (Breedy and Guzman, 2003, 2002; Guzman and Breedy, 2012). About two-thirds Pacifigorgia species, including at least six endemic species restricted to the shallow waters of the Gulf of Chiriquí, Panama, occur in the Panamic province (from $\sim 16^{\circ} \mathrm{N}$ to $\sim 3^{\circ}$ N) (Guzman et al., 2004; Vargas et al., 2008). This marked increase in species number toward lower latitudes in Pacifigorgia is consistent with the latitudinal diversity gradient reported for shallow-water eastern Pacific octocorals (Núñez-Flores et al., 2019) and likely drives it. Thus, clarifying the mechanisms of speciation that resulted in the high diversity of Pacifigorgia in the Panamic province is pivotal to understand how evolutionary processes shaped the octocoral diversity patterns observed in the region.

In contrast to most octocoral genera, Pacifigorgia has been the subject of intense morphological and molecular research. Breedy and Guzman (2002) thoroughly revised the genus and later described many new species (Breedy, 2001; Breedy and Guzman, 2004, 2003; Breedy and Guzmán, 2003; Guzman and Breedy, 2012). Molecular phylogenetic studies of Pacifigorgia are also available, yet species-level relationships within Pacifigorgia remain poorly resolved due to the lack of resolution of both mitochondrial (i.e., mtMutS) and nuclear markers (e.g., $28 \mathrm{~S}$ rDNA) at this level (AmentVelásquez et al., 2016; Soler-Hurtado et al., 2017; Vargas et al., 2014). 
bioRxiv preprint doi: https://doi.org/10.1101/2021.04.29.442007; this version posted April 29, 2021. The copyright holder for this preprint (which was not certified by peer review) is the author/funder, who has granted bioRxiv a license to display the preprint in perpetuity. It is made available under aCC-BY 4.0 International license.

Despite the difficulties faced studying the diversification process in Pacifigorgia and other eastern Pacific octocorals (e.g., Leptogorgia and Eugorgia), some patterns arise from the molecular phylogenies available for the group. For instance, Ament et al. (2016) and Soler-Hurtado et al. (2017) proposed that hybridization could explain the mito-nuclear conflicts found in several eastern Pacific octocoral (holaxonian) genera. However, those authors' inability to exclude other processes resulting in similar branching patterns, such as incomplete lineage sorting after rapid diversification events, left those claims mostly speculative. Similarly, hypotheses on cryptic speciation within Pacifigorgia are most likely affected by the resolution and the number of phylogenetic markers used, and by the differences in taxon-sampling across phylogenies inferred using different markers (Ament-Velásquez et al., 2016; Soler-Hurtado et al., 2017; Vargas et al., 2014). Thus, the contribution of these processes to the diversification of eastern Pacific octocorals remains to be determined.

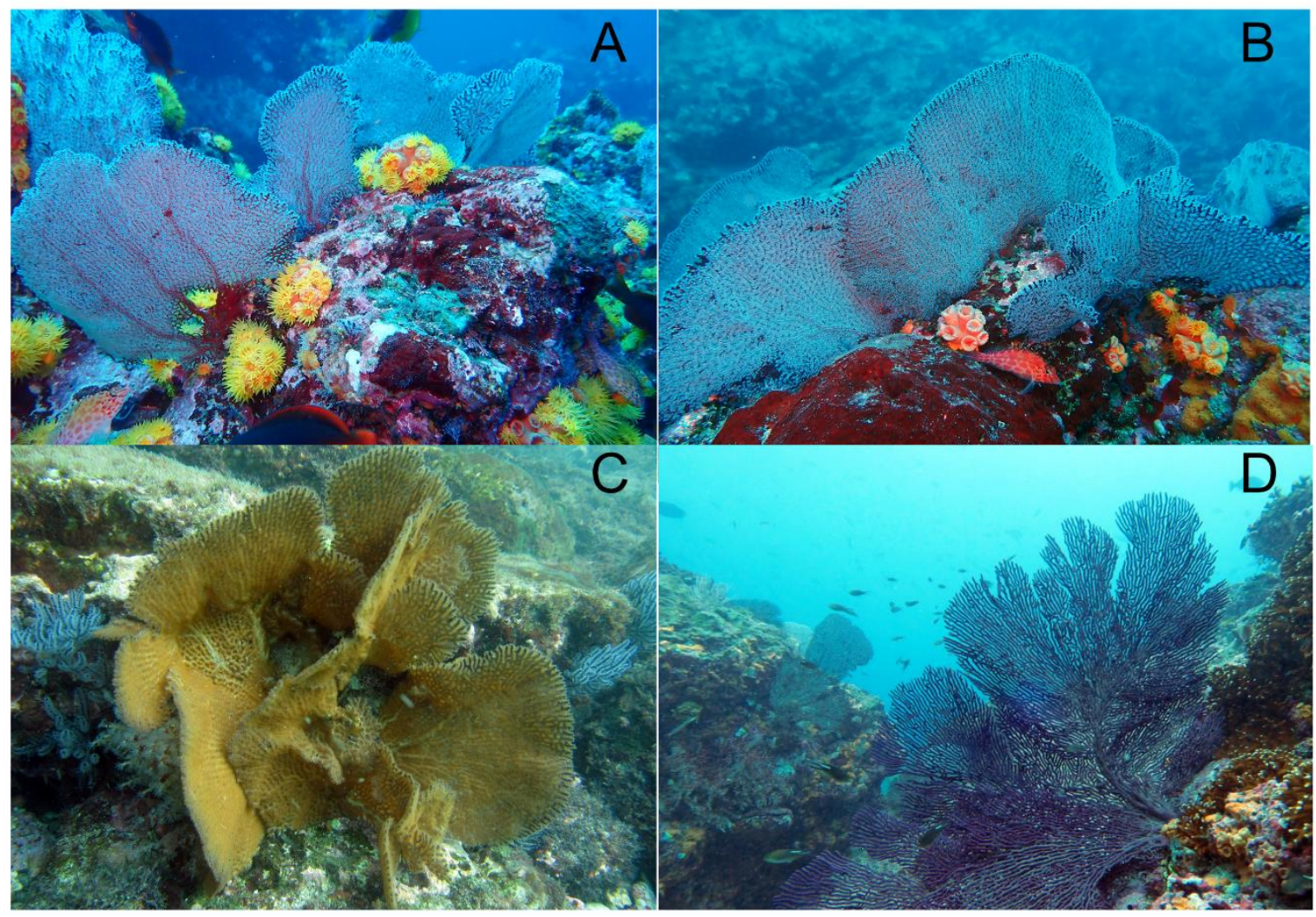

Fig. 1: In situ photographs of A) Pacifigorgia cairnsi, B) Pacifigorgia rubicunda, C) Pacifigorgia firma, and D) Pacifigorgia stenobrochis. Photo credits: $P$. cairnsi and P. rubicunda Kike Ballesteros, $P$. firma Jaime Nivia, $P$. stenobrochis Kevan Mantell.

Here, we use genome-wide, Single Nucleotide Polymorphisms (SNPs) and a collection of widespread and locally restricted Pacifigorgia species from the Gulf of Chiriquí, Panama, a biodiversity hot-spot for this genus (Guzman et al., 2004; Guzman and Breedy, 2008), to assess the contribution of hybridization and cryptic speciation to the diversification process in Pacifigorgia. We detected hybridization events and several instances of cryptic speciation among the Pacifigorgia species sampled. Our results provide conclusive evidence for reticulation among eastern Pacific octocorals and pose new challenges for better studying the diversity and distribution of these organisms.

\section{Materials and Methods}

We collected by SCUBA diving 82 specimens belonging two genera and ten species ( $P$. bayeri, $P$. cairnsi, $P$. eximia, $P$. ferruginea, $P$. firma, $P$. rubicunda, $P$. smithsoniana, $P$. stenobrochis, and Leptogorgia pumila and Leptogorgia taboguillae) from six different localities in the Coiba National 
Park, Panama (S. Fig. 1). Sampling depths ranged from $8 \mathrm{~m}$ to $24 \mathrm{~m}$. Upon sampling, we sorted and morphologically identified all specimens in the field before preserving them in absolute ethanol until further processing.

We extracted gDNA using a standard CTAB protocol (Porebski et al., 1997), and quality controlled the extracts on $1.5 \%$ agarose gels. We checked the yield and purity of the extracts using a NanoDrop 2100. If needed, we digested RNA with RNase $A$ and cleaned the resulting RNA-free extracts using a standard sodium acetate-ethanol precipitation. Of the 82 specimens extracted, only 40 yielded high molecular weight DNA. We used these specimens to prepare reduced representation libraries following the Genotyping-by-Sequencing (GBS) protocol of Elshire et al. (2011). Briefly, for each specimen, we digested $\sim 150 \mathrm{ng}$ of gDNA with Apekl for two hours at $75^{\circ} \mathrm{C}$ and ligated the resulting fragments (one hour at $22^{\circ} \mathrm{C}$ ) to one "common" and one barcoded adapter. We stopped the ligation reaction by heating the samples at $65^{\circ} \mathrm{C}$ for 30 minutes and we amplified ( 15 cycles; annealing temperature of $65^{\circ} \mathrm{C}$ and extension time of 30s) the adapter-ligated fragments using a universal nonbarcoded primer (GBS_PrimerA) and a different barcoded primer for each sample. We purified the PCR products using 1.1 volume Agencourt AMPure XP beads (Beckman Coulter, Inc.) and quantified them using a QUBit ${ }^{\circledast} 2.0$ fluorometer with a dsDNA HS Assay Kit (Invitrogen, Carlsbad, CA). Before sequencing, we pooled the libraries at equimolar concentrations and performed a final quality check using a Bioanalyzer 2100 (Agilent, Santa Clara, CA). The library pool was adjusted at a concentration of $10 \mathrm{nM}$ and sequenced on two lanes of an Illumina HiSeq 2500 (Illumina, San Diego, CA) using 100bp single-end chemistry. The raw sequence reads are available under study accession PRJEB44220.

We demultiplexed, quality controlled, filtered, and trimmed to 80 -bp the $~ 300 \times 10^{6}$ sequence reads obtained from the two HiSeq lanes. We determined SNPs de novo with IPYRAD (Eaton and Overcast, 2020) using a clustering threshold of 0.85 , maximum 20 SNPs and eight gaps per loci, and a minimum depth of six reads for base calling. These parameters have been successfully used in previous studies using RAD-Seq on octocorals (Herrera and Shank, 2016; e.g., Pante et al., 2015; Quattrini et al., 2019). For phylogenetic inference, we first produced an alignment containing loci present in at least $10 \%$ of the taxa (i.e., four specimens) and then discarded columns with $>20 \%$ gaps to produce an alignment containing 122,464 sites present in at least 32 of 40 specimens. We used this alignment to infer a maximum likelihood phylogeny in the program RAxML v8.2.12 (single partition GTRGAMMA+F, 1000 fast bootstrap replicates, Stamatakis, 2014). We estimated a SNP matrix using the same parameters described above but including only those SNPs present in at least $50 \%$ of the taxa (i.e., 20 specimens). We used this matrix to find specimen groups in a phylogenetic independent way using Discriminant Analysis of Principal Components (DAPC) analyses (Jombart et al., 2010). We used the package adegenet (Jombart, 2008), 10 Principal Components, and the method find.clusters to select the most probable number of species groups via BIC. For each specimen, we also calculated its group assignment probability. To test for hybridization in Pacifigorgia, we used IPyRAD to conduct ABBABABA tests on the best maximum likelihood phylogeny and the SNPs dataset estimated for phylogeny-independent analyses. The data matrices are publicly available at https://gitlab.Irz.de/palmuc/pacifigorgia-gbs

\section{Results and Discussion}

Previous molecular phylogenetic studies of eastern Pacific octocorals recovered Pacifigorgia monophyletic but could not resolve its species-level relationships (Ament-Velásquez et al., 2016; SolerHurtado et al., 2017; Vargas et al., 2014). In contrast, we recovered a maximum likelihood phylogeny generally showing branch support values $>75 \%$ (Fig. 2) and clades corresponding to recently revised and described Pacifigorgia species, such as $P$. eximia and $P$. bayeri. These species are morphologically well-defined and can be accurately identified in the field and laboratory (Breedy and Guzman, 2004, 2003). Accordingly, these species belonged to clearly defined DAPC groups, and we could not detect 
bioRxiv preprint doi: https://doi.org/10.1101/2021.04.29.442007; this version posted April 29, 2021. The copyright holder for this preprint (which was not certified by peer review) is the author/funder, who has granted bioRxiv a license to display the preprint in perpetuity. It is made available under aCC-BY 4.0 International license.

introgression between these species and specimens of other Pacifigorgia clades. Thus, our genomewide GBS data further support their species-level status.

Our phylogeny also recovered well-supported clades grouping individuals assigned to different morphologically defined species. For instance, we detected a group composed of individuals assigned to P. stenobrochis and Leptogorgia pumila (Fig. 2). Ament et al. (2016) also found this same grouping using partial mtMutS and 28S rDNA sequences and proposed to transfer L. pumila to Pacifigorgia. However, such taxonomic decision requires the amendment of Pacifigorgia's diagnosis to include nonanastomosing or loosely anastomosing species, an act that will let the genus so poorly defined that it could, in principle, include all Leptogorgia species hitherto described. Within this clade, DAPC assigned $L$. pumila to groups one and three and $P$. stenobrochis specimens to groups one, twelve, and thirteen (Fig. 2). Groups one and twelve likely are in admixture; $P$. stenobrochis specimens have high group membership probability for either group. Group thirteen appears to encompass specimens with high levels of missing data in the SNP matrix (S. Fig 2) and should be taken cautiously. We detected introgression between all specimens identified morphologically as L. pumila (Fig. 2 and S. Fig. 3) despite the phylogenetic tree pointing to a closer phylogenetic relationship between some $P$. stenobrochis and $L$. pumila specimens and the assignment of $L$. pumila specimens to different DAPC groups.
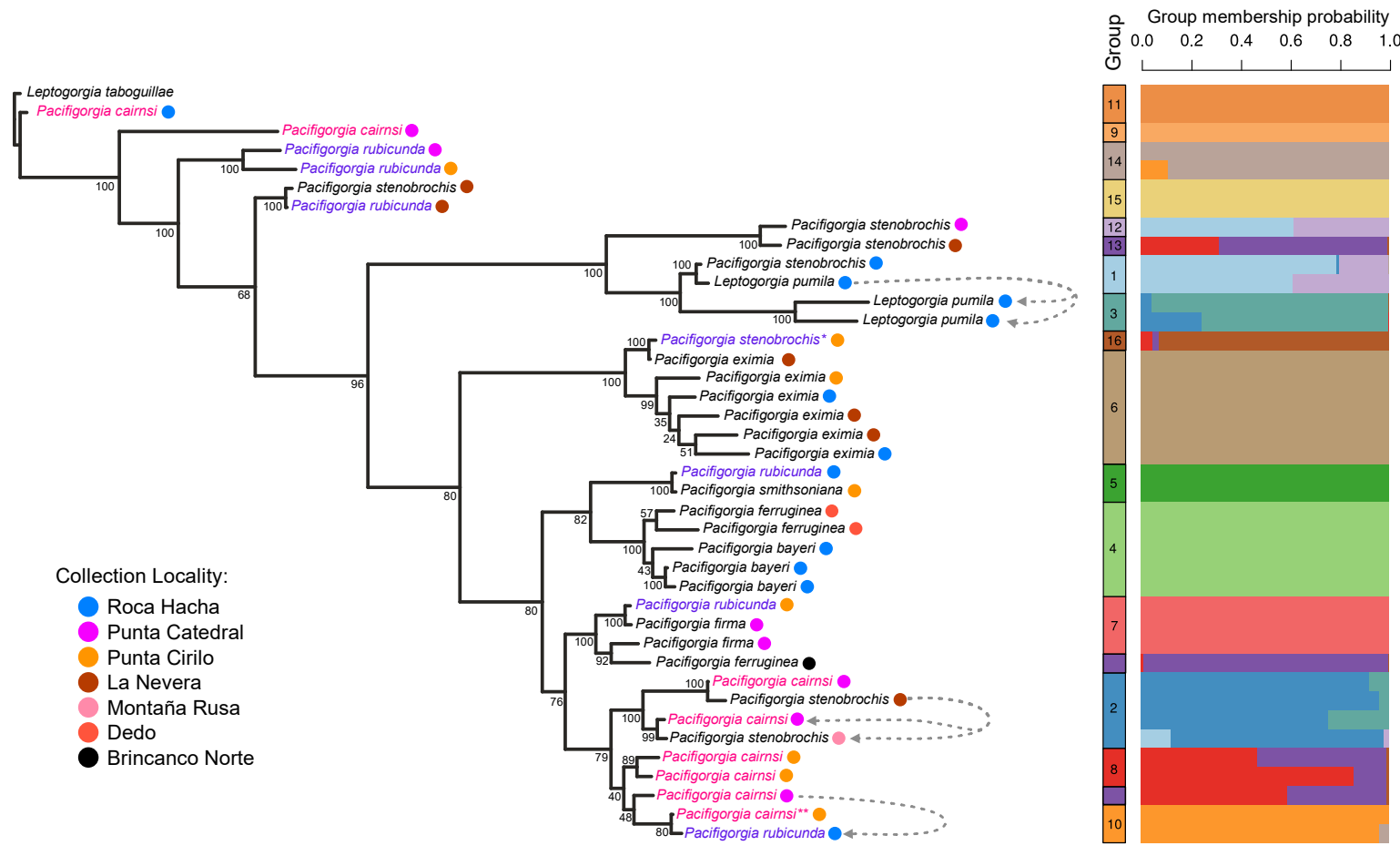

Similarly, we detected a well-supported clade grouping specimens of $P$. carnsi and $P$. stenobrochis (Fig.

Fig. 2: Maximum likelihood phylogeny of Pacifigorgia based on 122,464 genome-wide SNP markers. Numbers below the branches represent bootstrap support values. Pacifigorgia cairnsi and Pacifigorgia rubicunda, two widespread species, are highlighted in light red and purple blue, respectively. Gray dashed arrows indicate introgression events detected using ABBA-BABA tests on the maximum-likelihood topology. On the right, group assignments and group membership probabilities of different Pacifigorgia specimens obtained using DAPC of the SNPs matrix. ${ }^{*} P$. stenobrochis and ${ }^{*} P$. cairnsi colonies with anomalous sclerome and DAPC group assignments. 2). DAPC assigned all four specimens included in this clade to the same group, and we detected introgression between them (S. Fig. 4). These results indicate that this group's specimens, although assigned to different morphological species, are in admixture. Previous DNA barcoding studies also 
revealed multiple $P$. stenobrochis clades in the eastern Pacific (Vargas et al., 2014). We recovered four not closely-related clades and an equal number of DAPC groups including $P$. stenobrochis specimens, further pointing to the existence of cryptic lineages within this species. Some of these clades and groups include "typical" $P$. stenobrochis individuals while other consist of specimens differing in colony shape or spiculation from this species' type (e.g. DAPC Group 16 P. stenobrochis). Despite its very characteristic colony morphology, $P$. stenobrochis displays some variation in the mesh, and two recognized color morphs can be observed in the same colony. The species' sclerome is also variable, with either spindles or blunt spindles as the dominant sclerite form (Breedy and Guzman, 2004, 2002). However, in phenotypically very plastic organisms like octocorals (Calixto-Botía and Sánchez, 2017; Prada et al., 2008; West et al., 1993), it is hard to justify solely based on morphology the segregation of $P$. stenobrochis into multiple species with slightly different coloration, sclerome or colony shapes, or based on the occasional collection of specimens not fitting perfectly the $P$. stenobrochis gestalt. Our results indicate that a taxonomic reevaluation of $P$. stenobrochis' different morphs is warranted and provide an integrative framework to morphologically describe new species leveraging high-resolution, genome-wide markers.

Our phylogenetic results supported clades including specimens of $P$. rubicunda and $P$. cairnsi, and of $P$. rubicunda and $P$. stenobrochis (Fig. 2). These clades also corresponded to DAPC groups (i.e., groups 10 and 15). The morphology of the specimens included in these groups was typical; the specimen of $P$. cairnsi had a somewhat divergent sclerome dominated by spindles. Pacifigorgia rubicunda is morphologically diverse, with colonies consisting of single fans or forming rosettes. This species coexists with $P$. cairnsi and $P$. stenobrochis throughout its geographic range (Breedy and Guzman, 2003, 2002). We found evidence for introgression between $P$. cairnsi and P. rubicunda (Fig. 2 and S. Fig. 5), which are morphologically different. However, this hybridization event involves one $P$. cairnsi specimen assigned to group thirteen, a group joining mainly specimens with many missing SNPs, and a clade with internal low bootstrap support values (Fig. 2). Therefore, this introgression event should be taken cautiously. Beside these mixed clades, we found highly supported clades of $P$. cairnsi and $P$. rubicunda specimens collected in different localities interspersed in the tree (Fig. 2). DAPC also supported these clades (e.g., group 14). We could not detect introgression for these clades, which likely represent cryptic lineages within $P$. cairnsi and $P$. rubicunda, two species with a wide geographic distribution (Breedy and Guzman, 2003).

We observed a similar phenomenon for the specimens of $P$. firma included in the analyses, which did not form a clade but grouped with specimens of $P$. rubicunda and $P$. ferruginea (Fig. 2). Except for $P$. ferruginea, DAPC assigned this clade's specimens to group seven. We could not find any evidence for introgression within this clade, suggesting that $P$. ferruginea and $P$. firma currently include multiple evolutionary lineages (S. Fig. 6). Pacifigorgia ferruginea is endemic to the Gulf of Chiriqui and generally easy to identify in the field by its characteristic rusty appearance. In our phylogenetic analysis, $P$. ferruginea specimens from Dedo did not group with the single specimen collected in the nearby Brincanco Norte island, suggesting that cryptic species can occur within potentially very short geographic scales in Pacifigorgia. However, given the assignment of the single specimen of $P$. ferruginea from Brincanco Norte to DAPC group thirteen and a large number of missing SNP loci in this specimen, this interpretation should be corroborated in future studies. Pacifigorgia firma is widely distributed and morphologically variable (Breedy and Guzman, 2003). Despite its morphological plasticity and the continuous nature of most characters used to define the species, $P$. firma can be accurately determined. The finding of specimens morphologically assigned to $P$. rubicunda within a highly supported $P$. firma clade and DAPC highlights the challenges in establishing a morphologicalmolecular classification of Pacifigorgia. In particular, in morphologically highly variable and widespread species such as $P$. rubicunda, defining the extent to which hybridization contributes to the generation 
of new Pacifigorgia lineages and the molecular and morphological boundaries of those species remains to be determined.

Hybridization occurs in several scleractinian coral and octocoral lineages and is thought to be an important speciation mechanism in these groups (Mao, 2020). In scleractinian corals, hybridization between species with overlapping distribution ranges explains the large number of morphological species observed in important West and East Pacific reef-builders such as Acropora (Van Oppen et al., 2002) and Pocillopora (Combosch and Vollmer, 2015), respectively. In octocorals, McFadden and Hutchinson (2004) found evidence for hybridization in Alcyonium and Quattrini et al. (2019) found evidence of both morphological diversification in the absence of molecular divergence and hybridization in Sinularia. In this genus, local hybrids can become highly abundant, replacing their parental lines and changing community composition overtime (Slattery et al., 2008). Thus, other than evolutionary dead-ends, coral and octocoral hybrids represent evolutionary experiments capable of affecting the entire ecosystem. In the specific case of Pacifigorgia, the poor congruence between some morphological species and molecular groups we inferred using an extensive, genome-wide marker set indicates that genotyping specimens throughout a species' geographic range is necessary to unveil morphologically cryptic and hybrid Pacifigorgia lineages and uncover the "true" diversity of this species-rich genus. Additionally, identifying differences in the reproductive cycles and strategies among different Pacifigorgia species and their populations is of crucial importance for better linking the molecular results with the reproductive ecology and natural history of these organisms (Gomez et al., 2018). In conjunction, our study suggests that the diversity of eastern Pacific Pacifigorgia is larger than currently recognized. Neutral processes such as the mid-domain effect cannot explain the diversity patterns observed for eastern Pacific octocorals (Núñez-Flores et al., 2019). Our data indicate that hybridization and cryptic speciation shape Pacifigorgia's diversification history and likely are the drivers of the octocoral diversity patterns observed in the Tropical Eastern Pacific.

\section{Acknowledgments}

We thank Andrea Quattrini for commenting an early version of the manuscript and providing valuable feedback on the interpretation of the analyses. We thank Prof. Gert Wörheide for providing access to laboratory facilities at the Dept. of Earth and Environmental Sciences, Geobiology \& Paleontology (Ludwig-Maximilians-Universität München). We thank Dr. Stefan Krebs and Dr. Helmuth Blum (Ludwig-Maximilians-Universität, München) for technical support and sequencing the GBS libraries. The project was partially supported by the LMU München German Excellence Initiative Junior Research Funds to SV, the Smithsonian Tropical Research Institute, and the Secretaria Nacional de Ciencias y Tecnologia (SENACYT) de Panamá to HMG. The Ministerio de Ambiente de Panamá issued collection and exporting permits of eastern Pacific material. We thank C. Guevara and K. Mantell for their support during field collections. SV thanks N. Villalobos Trigueros, M. Vargas Villalobos, S. Vargas Villalobos, and S. Vargas Villalobos for their constant support.

\section{Author contributions}

AP: Investigation, Formal Analysis, Data curation, Visualization, Writing - Original Draft. OB: Conceptualization, Investigation, Resources, Writing - Review \& Editing, Project Administration. HMG: Resources, Funding Acquisition, Writing - Review \& Editing, Project Administration. SV: Conceptualization, Methodology, Formal Analysis, Visualization, Writing - Original Draft, Resources, Supervision, Project Administration, Funding Acquisition. 
bioRxiv preprint doi: https://doi.org/10.1101/2021.04.29.442007; this version posted April 29, 2021. The copyright holder for this preprint (which was not certified by peer review) is the author/funder, who has granted bioRxiv a license to display the preprint in perpetuity. It is made available under aCC-BY 4.0 International license.

\section{References}

Ament-Velásquez, S.L., Breedy, O., Cortés, J., Guzman, H.M., Wörheide, G., Vargas, S., 2016. Homoplasious colony morphology and mito-nuclear phylogenetic discordance among Eastern Pacific octocorals. Mol. Phylogenet. Evol. 98, 373-381.

Breedy, O., 2001. A new species of Pacifigorgia from the eastern Pacific (Coelenterata: Octocorallia: Gorgoniidae). Bullentin of the Biological Society of Washington 10, 181-187.

Breedy, O., Guzman, H.M., 2004. New species of the gorgoniian genus Pacifigorgia (Coelenterata: Octocorallia: Gorgoniidae) from Pacific Panama. Zootaxa 541, 1.

Breedy, O., Guzman, H.M., 2003. Octocorals from Costa Rica: The genus Pacifigorgia (Coelenterata: Octocorallia: Gorgoniidae). Zootaxa 281, 1.

Breedy, O., Guzmán, H.M., 2003. A new species of Pacifigorgia (Coelenterata: Octocorallia: Gorgoniidae) from Panamá. Zootaxa 128, 1-10.

Breedy, O., Guzman, H.M., 2002. A revision of the genus Pacifigorgia (Coelenterata : Octocorallia : Gorgoniidae). Proceedings of The Biological Society of Washington 115, 782-839.

Calixto-Botía, I., Sánchez, J.A., 2017. A case of modular phenotypic plasticity in the depth gradient for the gorgonian coral Antillogorgia bipinnata (Cnidaria: Octocorallia). BMC Evol. Biol. 17, 55.

Combosch, D.J., Vollmer, S.V., 2015. Trans-Pacific RAD-Seq population genomics confirms introgressive hybridization in Eastern Pacific Pocillopora corals. Mol. Phylogenet. Evol. 88, 154-162.

Eaton, D.A.R., Overcast, I., 2020. ipyrad: Interactive assembly and analysis of RADseq datasets. Bioinformatics 36, 2592-2594.

Elshire, R.J., Glaubitz, J.C., Sun, Q., Poland, J.A., Kawamoto, K., Buckler, E.S., Mitchell, S.E., 2011. A robust, simple genotyping-by-sequencing (GBS) approach for high diversity species. PLoS One 6, e19379.

Gomez, C.G., Gonzalez, A., Guzman, H.M., 2018. Reproductive traits and their relationship with water temperature in three common octocoral (Anthozoa: Octocoralia) species from the tropical eastern Pacific. Bull. Mar. Sci. 94, 1527-1541.

Guzman, H.M., Breedy, O., 2012. Pacifigorgia marviva (Anthozoa: Octocorallia) a new species from Coiba National Park, Pacific Panama. J. Mar. Biol. Assoc. U. K. 92, 693-698.

Guzman, H.M., Breedy, O., 2008. Distribución de la Diversidad y Estado de Conservación de los Arrecifes Coralinos y Comunidades Coralinas del Pacífico Occidental de Panamá (Punta MalaPunta Burica). The Nature Conservancy, 40p.

Guzman, H.M., Guevara, C.A., Breedy, O., 2004. Distribution, diversity, and conservation of coral reefs and coral communities in the largest marine protected area of Pacific Panama (Coiba Island). Environ. Conserv. 31, 111-121.

Herrera, S., Shank, T.M., 2016. RAD sequencing enables unprecedented phylogenetic resolution and objective species delimitation in recalcitrant divergent taxa. Mol. Phylogenet. Evol. 100, 7079.

Jombart, T., 2008. adegenet: a R package for the multivariate analysis of genetic markers. Bioinformatics 24, 1403-1405.

Jombart, T., Devillard, S., Balloux, F., 2010. Discriminant analysis of principal components: a new method for the analysis of genetically structured populations. BMC Genet. 11, 94.

Mao, Y., 2020. Genomic insights into hybridization of reef corals. Coral Reefs 39, 61-67.

McFadden, C.S., Hutchinson, M.B., 2004. Molecular evidence for the hybrid origin of species in the soft coral genus Alcyonium (Cnidaria: Anthozoa: Octocorallia). Mol. Ecol. 13, 1495-1505.

Núñez-Flores, M., Solórzano, A., Hernández, C.E., López-González, P.J., 2019. A latitudinal diversity gradient of shallow-water gorgonians (Cnidaria: Octocorallia: Alcyonacea) along the Tropical Eastern Pacific Ocean: testing for underlying mechanisms. Mar. Biodivers. 49, 2787-2800.

Pante, E., Abdelkrim, J., Viricel, A., Gey, D., France, S.C., Boisselier, M.C., Samadi, S., 2015. Use of RAD sequencing for delimiting species. Heredity 114, 450-459.

Porebski, S., Bailey, L.G., Baum, B.R., 1997. Modification of a CTAB DNA extraction protocol for plants containing high polysaccharide and polyphenol components. Plant Mol. Biol. Rep. 15, 8-15. 
bioRxiv preprint doi: https://doi.org/10.1101/2021.04 29.442007; this version posted April 29, 2021. The copyright holder for this preprint (which was not certified by peer review) is the author/funder, who has granted bioRxiv a license to display the preprint in perpetuity. It is made available under aCC-BY 4.0 International license.

Prada, C., Schizas, N.V., Yoshioka, P.M., 2008. Phenotypic plasticity or speciation? A case from a clonal marine organism. BMC Evol. Biol. 8, 47.

Quattrini, A.M., Wu, T., Soong, K., Jeng, M.-S., Benayahu, Y., McFadden, C.S., 2019. A next generation approach to species delimitation reveals the role of hybridization in a cryptic species complex of corals. BMC Evol. Biol. 19, 116.

Slattery, M., Kamel, H.N., Ankisetty, S., Gochfeld, D.J., Hoover, C.A., Thacker, R.W., 2008. Hybrid vigor in a tropical pacific soft-coral community. Ecol. Monogr. 78, 423-443.

Soler-Hurtado, M.M., López-González, P.J., Machordom, A., 2017. Molecular phylogenetic relationships reveal contrasting evolutionary patterns in Gorgoniidae (Octocorallia) in the Eastern Pacific. Mol. Phylogenet. Evol. 111, 219-230.

Stamatakis, A., 2014. RAxML version 8: a tool for phylogenetic analysis and post-analysis of large phylogenies. Bioinformatics 30, 1312-1313.

Van Oppen, M.J.H., Willis, B.L., Van Rheede, T., Miller, D.J., 2002. Spawning times, reproductive compatibilities and genetic structuring in the Acropora aspera group: evidence for natural hybridization and semi-permeable species boundaries in corals. Mol. Ecol. 11, 1363-1376.

Vargas, S., Guzman, H.M., Breedy, O., 2008. Distribution patterns of the genus Pacifigorgia (Octocorallia: Gorgoniidae): track compatibility analysis and parsimony analysis of endemicity. J. Biogeogr. 35, 241-247.

Vargas, S., Guzman, H.M., Breedy, O., Wörheide, G., 2014. Molecular phylogeny and DNA barcoding of tropical eastern Pacific shallow-water gorgonian octocorals. Mar. Biol. 161, 1027-1038.

West, J.M., Harvell, C.D., Walls, A.-M., 1993. Morphological plasticity in a gorgonian coral (Briareum asbestinum) over a depth cline. Mar. Ecol. Prog. Ser. 94, 61-69. 